D.O.I.: $10.3895 / \mathrm{S} 1808-04482008000100010$

\title{
IDENTIFICAÇÃO DOS NÍVEIS DE PRESSÃO SONORA EM SHOPPING CENTER'S NA CIDADE DE JOÃO PESSOA
}

\section{IDENTIFICATION OF SONOROUS PRESSURE LEVEL IN SHOPPING MALL IN THE CITY OF JOAO PESSOA}

\author{
Valéria de Sá Barreto Gonçalves ${ }^{1}$; Paulo José Adissi ${ }^{2}$ \\ ${ }^{1}$ Federal University of Paraíba - UFPB - João Pessoa - Brasil lelajp@terra.com.br \\ ${ }^{2}$ Federal University of Paraíba - UFPB - João Pessoa- Brasil adissi@ct.ufpb.br
}

\begin{abstract}
Resumo
A audição é um órgão sensorial pelo qual o organismo percebe as ondas mecânicas produzidas por vibração de um corpo, propagando-se através de moléculas de ar, ou seja, o som. Quando um som é indesejado e compromete a saúde e o bem estar das pessoas, este se chama ruído. $O$ objetivo deste trabalho foi verificar o nivel de pressão sonora existente em quatro Shopping Center's na cidade de João Pessoa e comparar com o permitido pela resolução/Conama/n. ${ }^{\circ} 001$, de 08 de março de 1990. A metodologia utilizada foi à coleta de dados sendo elaborada em etapas. O estudo é quantitativo de caráter transversal e exploratório. De acordo com a pesquisa realizada, foi constatada que o ruído está presente nos quatro locais de lazer na cidade de João Pessoa. Concluise que as pessoas que freqüentam estes locais desconhecem os índices de ruído, os limites máximos permitidos pela legislação, e ainda, os efeitos do ruído no organismo. Os dados coletados nesta pesquisa poderão servir de subsidios para mudanças de postura diante dos resultados apresentados.
\end{abstract}

Palavras-chave: níveis; pressão sonora; ruído.

\section{Introdução}

A cidade de João Pessoa, Capital do Estado da Paraíba, localiza-se na Região Nordeste do Brasil, e possui uma população estimada, segundo dados do Instituto Brasileiro de Estatística (IBGE, 2004), de 649.410 habitantes, distribuídas em nove regiões administrativas que totalizam 72 bairros.

O controle do ruído tem sido uma constante na cidade de João Pessoa. Devido a problemas pertinentes nesse setor, foi criada, sob o Código do Meio Ambiente, a Legislação Municipal, Lei $\mathrm{n}^{\circ}$ 29 de 05 de agosto de 2002 e Decreto 4793 de 21 de abril de 2003, que aborda os níveis permitidos de pressão sonora. Esta Lei é fundamentada na resolução do Conselho Nacional do Meio Ambiente 
(CONAMA) $n^{\circ}$ 001, de 08 de março de 1990, a qual estabelece padrões, critérios e diretrizes a serem observados na emissão de ruídos, que, em decreto publicado no Diário Oficial da União, de 02 de abril de 1990, Seção I, Pág. 6.408, cita a Norma Brasileira (NBR) 10.152/87. Segundo a qual constituem prejuízos à saúde e ao sossego público a emissão de ruídos, em decorrência de qualquer atividade industrial, comercial, social ou recreativa, inclusive as de propaganda política, os ruídos com níveis superiores aos considerados aceitáveis.

O ruído é, na maioria dos países, o agente nocivo mais prevalente nos ambientes de trabalho. Sua presença nas atividades laborais e em ambientes urbanos soma-se a sua intensa disseminação nos meios sociais, especialmente nas atividades de lazer. Essa propagação quase universal do ruído, nos ambientes sociais e de trabalho, gera maior preocupação quando se considera que o dano auditivo dele decorrente é irreversível, e que a exposição produz outros distúrbios: orgânicos; fisiológicos e psicoemocionais, resultando em uma evidente diminuição da qualidade de vida e de saúde da população.

A sensação que o ruído oferece de agradável/desagradável é subjetiva e depende da susceptibilidade individual; porém, o risco oferecido pelo ruído é objetivo e independe do grau de conforto/desconforto estabelecido individualmente. $\mathrm{O}$ volume do som não precisa ser alto para ser incômodo, e mesmo a música, que acusticamente não é considerada ruído por ser um som harmônico, pode, em determinadas condições, provocar desconforto na audição. No entanto, são comprovados os prejuízos que o efeito do ruído causa no organismo humano.

Pimentel-Souza (1992) estuda o problema de ruído tendo em vista o desempenho humano em condições de trabalho ou lazer, acarretando aumento do número de erros, acidentes e mortes. Assim a literatura indica a importância do assunto, bem como, o interesse em estudá-lo, diante das evidências de que a poluição sonora, de uma maneira geral, apresenta-se em níveis insalubres na maior parte das cidades.

O principal objetivo deste trabalho foi verificar o Nível de Pressão Sonora (NPS) existente em Shopping Center's na cidade de João Pessoa e comparar com o permitido pela resolução/Conama/n. ${ }^{\circ}$ 001, de 08 de março de 1990. Como objetivos específicos, serão abordados: a identificação do nível sonoro equivalente por meio de análise estatística segundo a NBR-10151/87 e a descrição da nocividade que os elevados níveis sonoros causam no organismo. Devido aos vários efeitos nocivos que os ruídos podem trazer ao ser humano, torna-se, então, importante o seu monitoramento e controle. A perda da audição é uma justificativa plausível para se considerar uma proposta de controle do ruído. 


\section{Revisão da Literatura}

\subsection{Poluição Ambiental e Ruído}

No âmbito da legislação ambiental, poluição é definida no art. $3^{\circ}$, III, da Lei 6.938/81, como a degradação da qualidade ambiental resultante de atividades que, direta ou indiretamente, prejudiquem a saúde, segurança e o bem estar da população; criem condições adversas às atividades sociais e econômicas; afetem as condições estéticas ou sanitárias do meio ambiente; lancem matérias ou energia em desacordo com os padrões ambientais estabelecidos. É importante salientar que a poluição sonora dá-se através do ruído que é um som indesejado que agride ao ouvido humano.

A Associação Brasileira de Normas Técnicas (ABNT) definiu ruído como sendo um fenômeno acústico dissonante ou anárquico, aperiódico e indesejável; mistura de sons cujas freqüências diferem entre si por valor inferior à discriminação em freqüências da orelha. O ruído é uma onda sonora aperiódica e, sendo assim, é muito difícil ou quase impossível prever a forma da onda em um intervalo de tempo, a partir do conhecimento de suas características, durante outro intervalo de tempo de igual duração. O movimento vibratório de uma onda aperiódica, como o ruído, ocorre ao acaso, é aleatório e, por esta razão, imprevisível.

O conceito de ruído é associado a som desagradável e indesejável. Som é definido como variação da pressão atmosférica dentro dos limites de amplitude e banda de freqüências aos quais o ouvido humano responde (GERGES, 1992). O ruído afeta o ser humano simultaneamente nos planos físico, psicológico e social. Os efeitos nele produzidos pela energia sonora vão desde uma ou mais alterações passageiras até graves danos irreversíveis.

Segundo Iida (1999), fisicamente, o ruído é uma mistura complexa de diversas vibrações, medido em uma escala logarítima, em uma unidade chamada de decibel (dB), podendo se destacar três características principais, que são a freqüência, a intensidade e a duração. A freqüência de um som é o número de flutuações ou vibrações por segundo e é expressa em hertz (Hz), subjetivamente percebida como altura do som. A intensidade do som depende da energia das oscilações e é definida em termos de potência por unidade de área. A duração do som é medida em segundos.

De acordo com a organização Mundial de Saúde (OMS, 1980 apud PIMENTEL-SOUZA, 1992) a partir de 65 decibel dB(A) o ruído inicia estresse leve, levando a uma excitação que já pode ser considerada como desconforto para quem necessita de tranqüilidade. $\mathrm{O}$ estresse degradativo do organismo começa em cerca de $70 \mathrm{~dB}$ (A), produzindo desequilíbrio bioquímico, aumentando o risco de hipertensão arterial e infarto do miocárdio, derrame cerebral, infecções, osteoporose e outras patologias. Acima de $75 \mathrm{~dB}$ (A) de exposição em torno de oito horas diárias, inicia-se o risco 
de comprometimento auditivo. Provavelmente a $80 \mathrm{~dB}$ (A) já ocorre liberação de endorfinas circulantes, provocando sensação paradoxal de prazer momentâneo. Em torno de 100 dB (A) pode haver imediata perda da audição.

Do ponto de vista físico, o som é uma alteração mecânica que se propaga em torno de movimento ondulatório através de um meio elástico (OPAS, 1983). As principais características do ruído são: a intensidade, que é a quantidade de energia vibratória que se propaga nas áreas próximas da fonte emissora e se expressa em termos de energia (watt/m2) ou em termos de pressão, Newton/m2, N/m2 ou Pascal); e a freqüência, que é representada pelo número de vibrações completas em um segundo, sendo sua unidade expressa em Hertz (Hz) (SANTOS, 1993).

A faixa de audibilidade percebida pelo ouvido humano varia de 0,00002 N/m2 (mínima pressão perceptível à freqüência de $1.000 \mathrm{~Hz}$ ) até valores muito elevados como $200 \mathrm{~N} / \mathrm{m} 2$ (limiar de dor), e para medir a pressão sonora, numa escala mais simples, utiliza-se uma relação logarítmica expressa em deciBel (dB) (SANTOS, 1993). Considera-se que o ruído seja um som não desejado que pode afetar de forma negativa a saúde e o bem estar de indivíduos ou populações (OPAS, 1983).

Como os níveis de ruído podem variar de maneira aleatória, utiliza-se freqüentemente medir o nível de pressão sonora contínua equivalente $\left(L_{e q}\right)$, expresso em $\mathrm{dB}$, que é uma integral de toda energia sonora durante um tempo "T" do som flutuante, equivalente a um valor de som constante, possuindo a mesma energia total ou dose (OMS, 1980; OPAS, 1983).

\subsection{Efeitos do ruído na audição e no organismo}

A exposição constante ao ruído pode causar diversos efeitos na saúde do indivíduo. Além das alterações no aparelho auditivo, são crescentes as evidências de que a exposição ao ruído poderá ser nociva a outros órgãos e sistemas.

Moraes e Regazzi (2002) referem que o ruído é um problema que acompanha o desenvolvimento da tecnologia, e seus efeitos se fazem sentir tanto nos locais de trabalho como nas comunidades. Podem-se destacar vários efeitos de interferências no ser humano.

Com base na Fundacentro (1995), as ações do ruído sobre o organismo humano podem-se dividir em: efeitos sobre o sistema auditivo (mudança temporária do limiar de audição; surdez permanente; trauma acústico); efeitos sobre o organismo em geral (perturbar circulação sangüínea e provocar efeitos psicológicos como o "stress"); efeitos sobre rendimento do trabalho (fadiga, falta de atenção, trazendo prejuízos para qualidade do produto e desperdício de tempo e material); A ocorrência de acidentes (causa indireta). O risco de lesão auditiva aumenta com o Nível de Pressão Sonora e com o tempo de exposição. Os níveis de ruído extremamente altos podem causar perda 
grave da audição. O efeito do ruído sobre a acuidade auditiva depende de certos fatores físicos e do sujeito afetado. Os fatores físicos compreendem as características qualitativas do ruído, tais como: intensidade (nível de pressão sonora), o tipo (contínuo, intermitente ou de impacto), faixa de freqüência, importando também a periodicidade, duração e distribuição ao longo do dia. Além disso, a susceptibilidade varia segundo os indivíduos. Alguns indivíduos têm maior ou menor tendência em adquirir perda auditiva nas mesmas condições de trabalho (MACEDO, 1988).

No aparelho auditivo, de acordo com Fiorini (1994), os efeitos do ruído na audição podem ser caracterizados como trauma acústico, que é um problema auditivo causado por uma única exposição a níveis sonoros muito intensos; mudança temporária do limiar, que consiste na redução do limiar auditivo logo após a exposição ao ruído, sendo esta uma diminuição da audição temporária, causada pela fadiga das células ciliadas externas. Tal redução no limiar auditivo é um fenômeno temporário, já que este volta ao normal após um período de repouso auditivo; essa mudança tende a ser recuperada nas primeiras duas a três horas depois de cessada a estimulação sonora; no entanto, freqüentes exposições ao ruído poderá vir a ocasionar uma mudança permanente no limiar auditivo que consiste em uma Perda Auditiva Induzida por Ruído (PAIR).

Os efeitos sobre o organismo humano, decorrentes da exposição contínua ao ruído, podem apresentar a seguinte classificação:

Os efeitos auditivos produzem causas fisiológicas, fisiopatológicas ou auditivas, compreendendo os efeitos otológicos, ou seja, a ação ocorre diretamente no sistema auditivo. O ouvido humano é sensível à ação do ruído. As lesões do ouvido interno, decorrentes da exposição contínua ao ruído, acarretam para o indivíduo esgotamento físico e alterações químicas, metabólicas e mecânicas (CARMO, 1999).

Os efeitos extra auditivos são resultantes de uma ação geral sobre diversas funções orgânicas. Segundo Carmo (1999), as principais manifestações que podem ocorrer são: aumento das freqüências cardíaca e respiratória, da pressão arterial, vasoconstrição periférica, vasodilatação cerebral, aumento da secreção da saliva, dilatação das pupilas, tensão muscular, aumento da liberação de hormônios das glândulas supra-renais (adrenalina, noradrenalina e cortisol). De acordo com Moraes e Regazzi (2002), as primeiras manifestações da ação do ruído são a inquietude, irritabilidade e alteração do metabolismo basal com distúrbios neuro musculares.

$\mathrm{Na}$ atividade cerebral, a capacidade do organismo em se ajustar a diversas formas de ruído deve-se à grande elasticidade e capacidade de adaptação do organismo humano aos estímulos do ambiente. Por ser proveniente de uma reação psicológica, a influência do ruído afeta as pessoas de maneiras diferentes, nem mesmo durante o repouso o homem fica livre da ação do ruído que age sobre o subconsciente e o sistema nervoso piorando sua saúde (MORAES E REGAZZI, 2002). 
Os ruídos intensos, acima de $90 \mathrm{~dB}$, dificultam a comunicação verbal. As pessoas precisam falar mais alto e prestar mais atenção, para serem compreendidas. Isso tudo faz aumentar a tensão psicológica e o nível de atenção. Os ruídos intensos tendem a prejudicar tarefas que exigem concentração mental e certas tarefas que exigem atenção ou velocidade de precisão dos movimentos, e os resultados tendem a piorar após duas horas de exposição ao ruído (IIDA, 1999).

Assim, o ruído poderá causar danos variados ao organismo, independentemente, se dentro do ambiente de trabalho ou fora deste.

\subsection{Ruído Urbano}

Todos os dias o ruído é introduzido no meio ambiente. São sons que provocam desconforto mental e físico, e que resultam de vibrações irregulares que podem afetar o equilíbrio sonoro, repercutindo sobre o sistema auditivo e as funções orgânicas.

Segundo Russo (1995), os habitantes das grandes cidades vivem dentro de uma atmosfera de ruídos, sofrendo a ação de um verdadeiro bombardeio sonoro, tanto nos momentos de distração/lazer, quanto no ambiente de trabalho.

No Brasil, a ABNT 10151 (1987) fixa os níveis máximos permitidos para diversos ambientes, indicando que são prejudiciais à saúde e ao sossego público, os ruídos com níveis superiores aos considerados aceitáveis pela norma NBR 10151 - Avaliação do Ruído em Área Habitada visando o conforto da comunidade. Os valores estabelecidos variam de acordo com o local; para restaurantes, considera-se $50 \mathrm{~dB}(\mathrm{~A})$, cinemas $45 \mathrm{~dB}(\mathrm{~A})$ e salas de esportes até $60 \mathrm{~dB}(\mathrm{~A})$. Entretanto, níveis superiores ao estabelecido são considerados de desconforto, sem necessariamente implicar em risco de dano à saúde.

Segundo a Organização Mundial de Saúde (OMS), o limite tolerável ao ouvido humano é de $65 \mathrm{~dB}(\mathrm{~A})$; acima disto, o nosso organismo sofre de estresse. Este, por sua vez, aumenta o risco de doenças, e com ruídos acima de $85 \mathrm{~dB}(\mathrm{~A})$ aumenta o risco de comprometimento auditivo.

O Ministério do Trabalho aborda que o ruído torna-se fator de risco da perda auditiva ocupacional se o nível de pressão sonora e o tempo de exposição ultrapassarem certos limites. A Norma Regulamentadora (NR) 15, da Portaria $n^{\circ} 3.214 / 78$, estabelece os limites de tolerância para a exposição a ruído contínuo ou intermitente e para ruído de impacto, vigentes no País. A máxima exposição diária permitida a nível de ruído é de $85 \mathrm{~dB}(\mathrm{~A})$ para oito horas de exposição. As atividades ou operações que expõem os trabalhadores a níveis de ruído contínuo ou intermitente, superiores a $115 \mathrm{~dB}(\mathrm{~A})$, sem proteção adequada, oferecem risco grave ou iminente (RODRIGUES, 2004).

O ruído é um agente nocivo prevalente em qualquer ambiente. Sua presença nas atividades laborais 
soma-se à sua intensa disseminação nos ambientes urbanos e sociais, especialmente nas atividades de lazer. De acordo com Ferreira Jr. (1998), ruído extra-ocupacional é o tipo de ruído que é emitido fora do ambiente de trabalho do individuo, cuja exposição contínua torna este individuo mais susceptível a adquirir uma perda auditiva induzida por ruído.

A perda orgânica da audição pode ser causada não só por ruído industrial, mas também por ruído da vida diária, como em jogos e lazer. Calcula-se que $10 \%$ da população do país possua distúrbios auditivos, sendo a rubéola responsável por 20\% dos casos (MELNICK, 1980). É comum encontrar-se o nível de $70 \mathrm{~dB}(\mathrm{~A})$ no meio urbano, onde o brasileiro é obrigado a falar 30 vezes mais elevado que o necessário, o que dificulta a comunicação, além de causar surdez ambiental (PIMENTEL-SOUZA, 1992; FIORINI et. al., 1994).

No mundo atual, há varias situações que promovem exposição a ruído, tais como: uso freqüente de aparelhos de som com fones de ouvido, freqüência a cultos religiosos, prática de esportes barulhentos como tiro ao alvo, uso freqüente de ferramentas ruidosas em trabalhos domésticos, alta intensidade em boates, ambientes como praças de alimentação, cinemas e shows, o que vem a justificar pesquisa nesta área.

\section{Material e Método}

No que se refere à caracterização da pesquisa, o estudo é quantitativo de caráter transversal e exploratório. Com base nos procedimentos técnicos de coleta e análises de dados, classifica-se como pesquisa prática e de levantamento de dados, ou seja, a coleta de campo.

O universo da pesquisa constituiu-se de uma amostra de quatro maiores Shopping Center's localizados na cidade de João Pessoa, para efetivação das medições de NPS. Para fins desta pesquisa os locais foram distribuídos em: Shopping 1, Shopping 2, Shopping 3 e Shopping 4.

Para a coleta de dados foi utilizado como instrumento medidor de NPS um instrumento tipo decibelímetro. Marca: Instrutherm. Modelo: Sound Level Meter. Fabricante: Instrutherm instrumentos de medição LTDA.

O equipamento é adequado para atender aos parâmetros de normalidade pela legislação brasileira em vigor para cálculo do NPS composto por: Circuito de ponderação "A"; Circuito de resposta "lenta, slow"; circuito de referência de $85 \mathrm{~dB}$; faixa de medição entre 80 a $115 \mathrm{~dB}(\mathrm{~A})$, a qual será utilizada nesta pesquisa. Este tipo de medidor é constituído por um sistema onde o microfone é uma peça vital, aliado a um amplificador e um indicador de nível de pressão sonora.

A coleta de dados foi elaborada em etapas. A primeira foi identificar o nível sonoro equivalente nos locais selecionados, nos dias de sexta, sábado e domingo por serem considerados dias de lazer, em horários pré-determinados entre 17:00 e 22:00, A segunda etapa foi analisar 
estatisticamente, segundo a NBR-10151/87. A terceira etapa foi comparar os resultados obtidos com a legislação em vigor.

A verificação do NPS existente em quatro Shopping Center's na cidade de João Pessoa ocorreu nos dias 20, 21 e 22 do mês de julho de 2007 e após esta, realizou-se a tabulação e análise de dados obtidos.

A partir da análise demonstrativa de todas as etapas anteriores, foi desenvolvido um estudo, apresentando os achados da pesquisa e como as conseqüências dos resultados podem contribuir para uma reflexão e mudança de conduta com relação ao ruído existente nas atividades de lazer. Todos os dados coletados foram interpretados e tabulados para a análise e conclusão da pesquisa.

\section{Resultados e Discussão}

\section{Resultados e Discussão}

Os dados foram analisados em forma de figuras, descrevendo as medições de NPS equivalente. A figura 1 descreve a diferença em $\mathrm{dB}(\mathrm{A})$, entre o nível de ruído encontrado e o permitido em shopping 1 descrito da seguinte maneira: Praça da Alimentação 1 Leq 90,1 dB(A); Praça da Alimentação 2 Leq 88,8 dB(A); sala de jogos eletrônicos Leq 91,6 dB(A); e oito salas de cinemas com valores entre $84,2 \mathrm{~dB}(\mathrm{~A})$ e $90,2 \mathrm{~dB}(\mathrm{~A})$; o resultado foram índices considerados elevados, ou seja, acima do limite máximo permitido pela ABNT 10152/87 que é de $50 \mathrm{~dB}(\mathrm{~A})$ para restaurantes, $60 \mathrm{~dB}(\mathrm{~A})$ para atividades esportivas e $45 \mathrm{~dB}(\mathrm{~A})$ para cinemas. $\mathrm{O}$ que se pode constatar nesta pesquisa é que os níveis de ruído existente nos ambientem descritos, se relacionar à freqüência e a intensidade de exposição ao ruído, podem causar efeitos diferentes no ser humano. Segundo Pimentel-Souza (1992), esses efeitos podem ser nulos a muito graves e vão depender da sensibilidade de cada indivíduo e do tempo de exposição. Pelos níveis médios de ruído medidos, devem está provocando incômodo na população. 


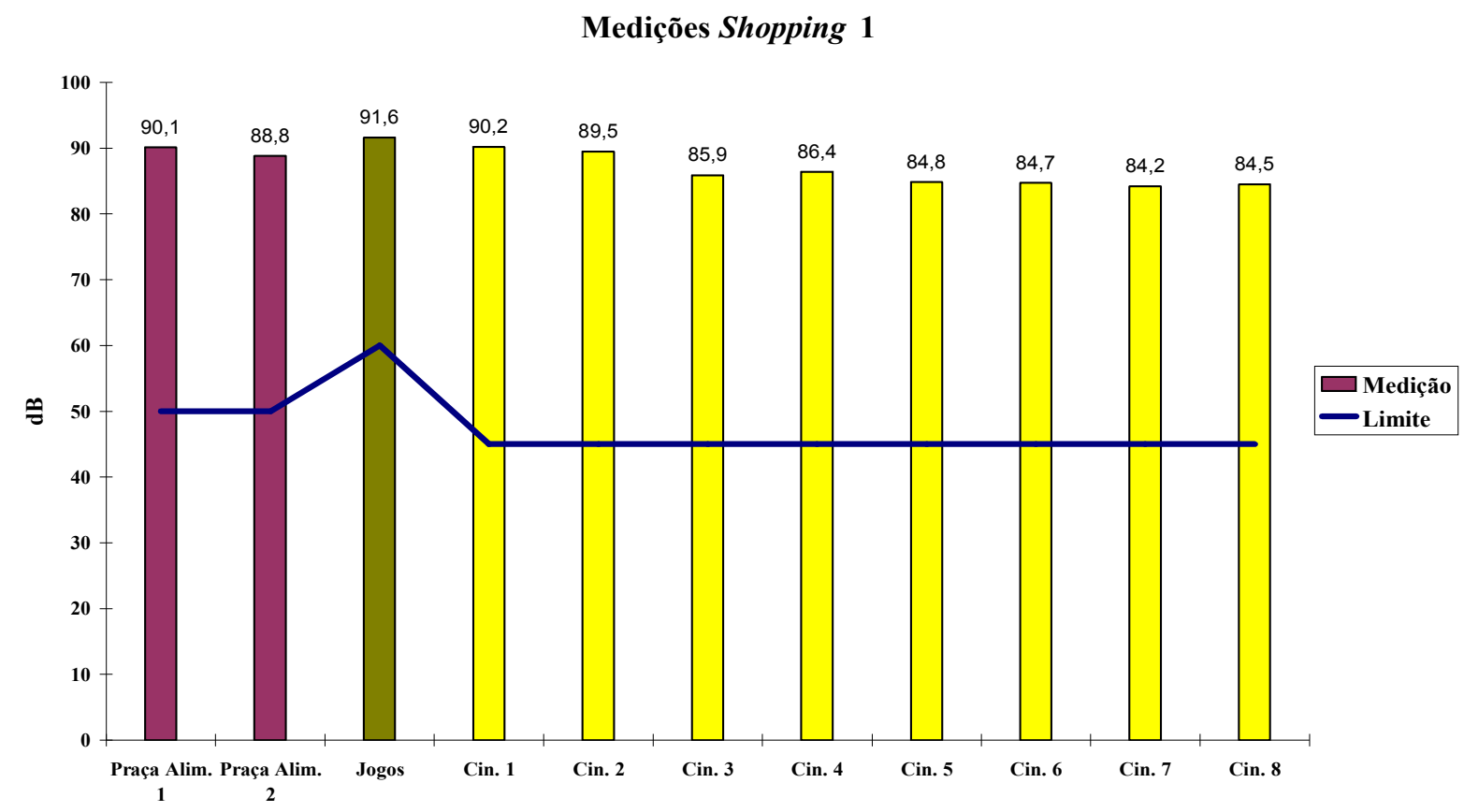

Fonte: Dados da pesquisa.

A figura 2 apresenta informações sobre o nível sonoro em medição do shopping 2 onde confirma os maiores índices de toda a pesquisa, demonstrando a necessidade de alerta as pessoas que ali trabalham. Da análise, conclui-se que os valores variam entre os ambientes avaliados descritos da seguinte maneira: praça da alimentação 1 Leq 92,2 dB(A); praça da alimentação 2 Leq $88,1 \mathrm{~dB}(\mathrm{~A})$; e o setor de cinemas variando entre $\operatorname{Leq} 75,1 \mathrm{~dB}(\mathrm{~A})$ e $L e q$ 90,1 dB(A); podendo ser constatado limites acima dos parâmetros permitido pela legislação. Quick e Lapertosa; Gomes (apud PIMENTEL-SOUZA, 1992), afirmam que o ruído excessivo nos trabalhadores tem sido constatado nesses últimos anos, através de: efeitos psicológicos, distúrbios neuro-vegetativos, náuseas, cefaléias, irritabilidade, instabilidade emocional, redução da libido, ansiedade, nervosismo, perda de apetite, sonolência, insônia, aumento da prevalência de úlcera, hipertensão, distúrbios visuais, consumo de tranqüilizantes, perturbações labirínticas, fadiga, redução da produtividade, aumento do número de acidentes, de consultas médicas, do absenteísmo. A exposição a níveis de pressão sonora elevados, bem como a de outros agentes, tem sido apontada como fator importante para o surgimento da perda auditiva progressiva e irreversível, que raramente é percebida no início, pois sua evolução é lenta e gradual e está relacionada com o tempo e o grau da exposição. 
Figura 2 - Medição Shopping Center 2

Medição Shopping 2

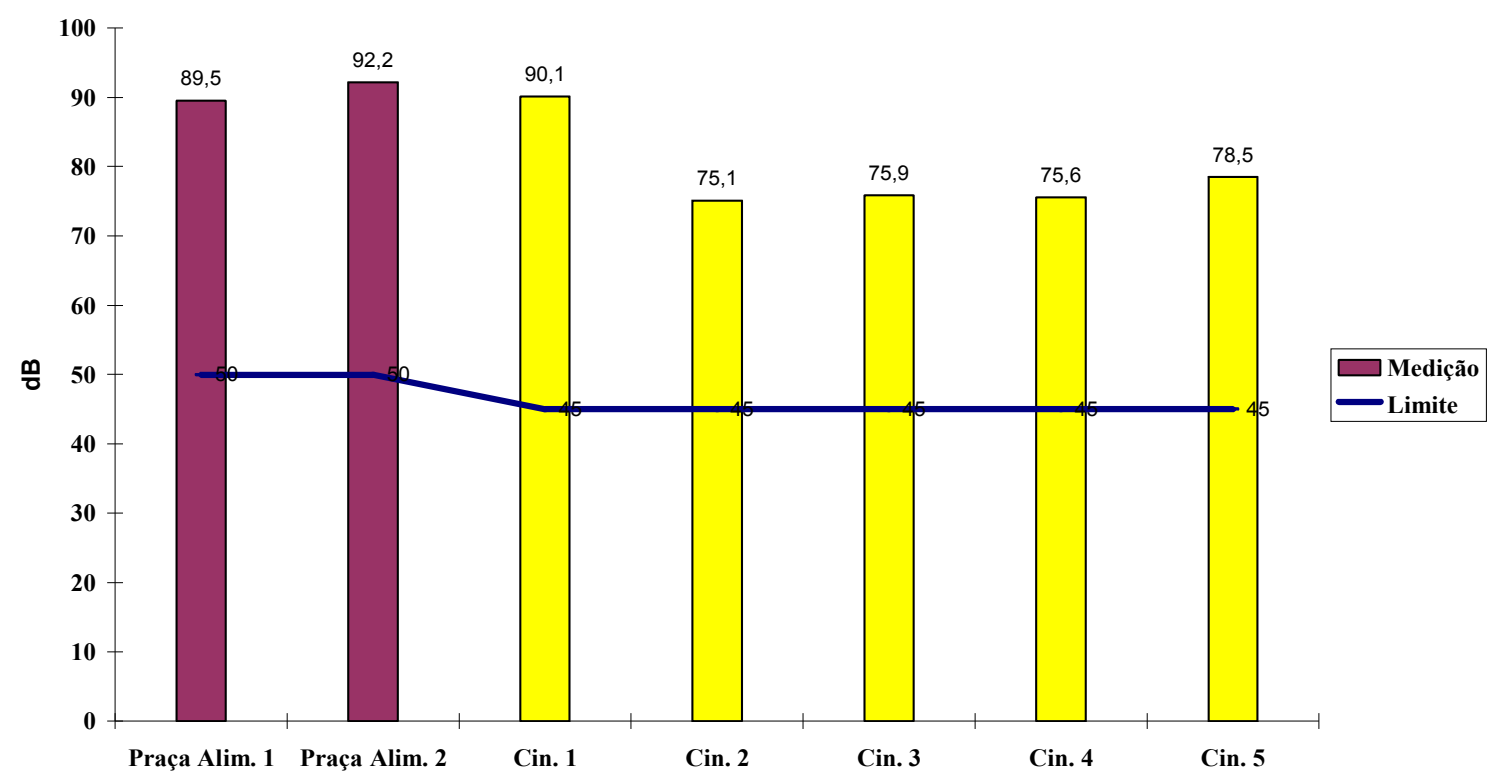

Fonte: Dados da pesquisa.

A figura 3 é o resultado da medição de nível sonoro equivalente a terceira área analisada denominada shopping 3 indicando valores acima do permitido pela legislação. Praça da alimentação Leq $85 \mathrm{~dB}(\mathrm{~A})$ jogos eletrônicos Leq $90.6 \mathrm{~dB}(\mathrm{~A})$ e cinemas variando em torno de $L e q$ 73,2 dB(A).e Leq 84,5 $\mathrm{dB}(\mathrm{A})$. Os ruídos estão abusivos, em infração à Lei Ambiental, porque os limites recomendados pela CONAMA 001 que segue a norma da ABNT (1987), estão entre 35 e 45 dB(A). Incomodando e ultrapassando o limite do saudável e afastando-se consideravelmente dos valores permitidos.

Figura 3 - Medição Shopping Center 3

Medição Shopping 3

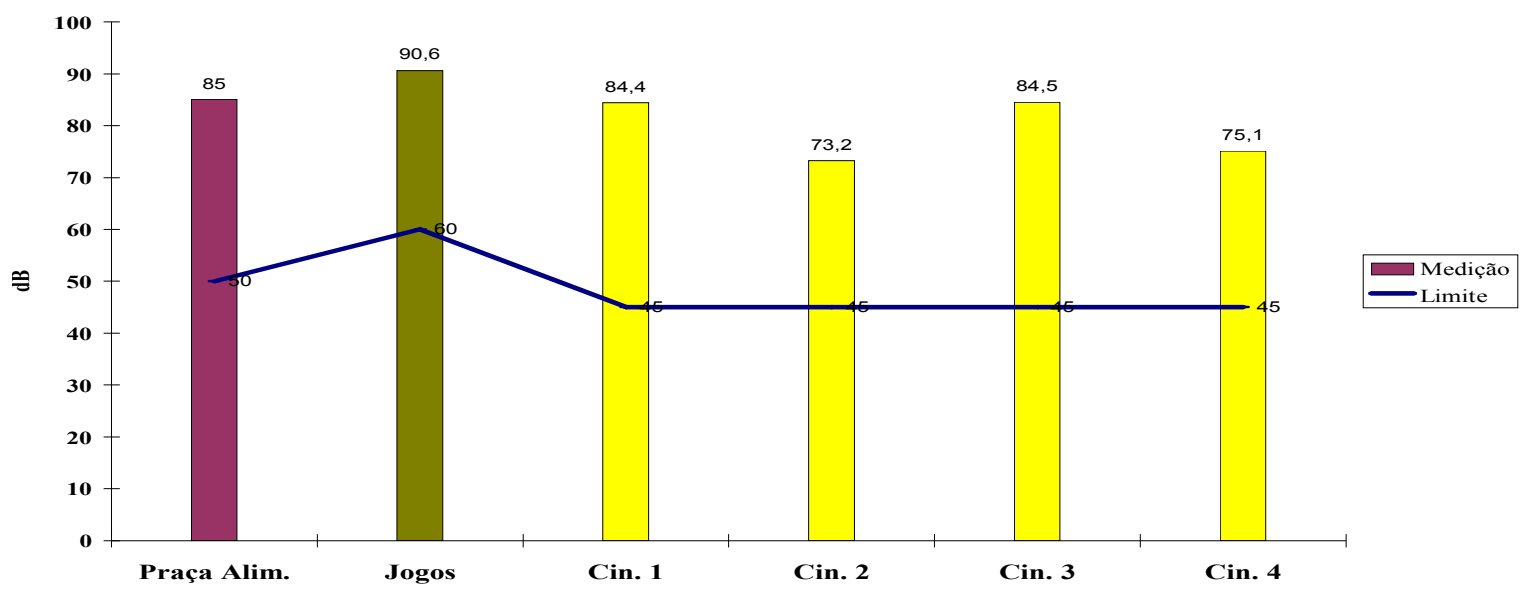

Fonte: Dados da pesquisa. 
$\mathrm{Na}$ análise da figura 4 pode-se observar que o nível sono encontrado na praça de alimentação, única diversão deste local, foi de $\operatorname{Leq} 89,5 \mathrm{~dB}(\mathrm{~A})$. O que se pode constatar nesta pesquisa é que, o nível de informação das pessoas que freqüentam estes locais desconhecem os índices de ruído, desconhecem também os limites máximos permitidos pela legislação, e ainda, os efeitos do ruído no organismo. O ruído é um agente nocivo prevalente em qualquer ambiente e nesta análise foi considerado acima dos limites de tolerância permitidos pela legislação em vigor. Em qualquer horário o ruído elevado é pertubador. Um pulso de som de $90 \mathrm{~dB}(\mathrm{~A})$ de apenas 20s desenvolve 80 s de constrição periférica nos vasos sanguíneos.

Figura 4 - Medição Shopping 4

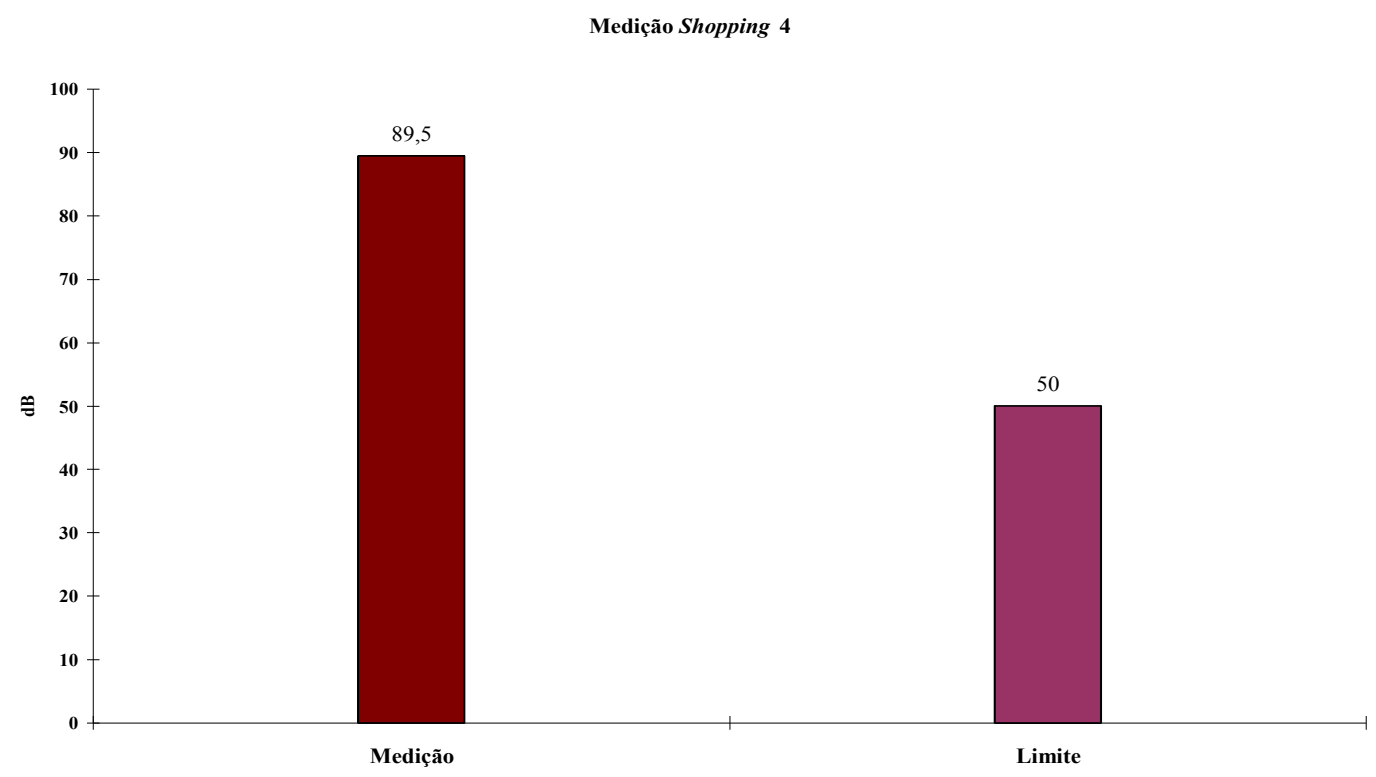

Fonte: Dados da pesquisa.

\section{Considerações Finais}

O desenvolvimento tecnológico atinge praticamente todas as atividades humanas, sejam elas sociais, de trabalho ou de lazer. Porém, além das vantagens dele decorrentes, aparecem vários subprodutos ou efeitos nocivos à qualidade de vida, individual ou coletiva, da população. Um dos subprodutos deste desenvolvimento é o ruído, o qual merece destaque por estar presente em muitas práticas de lazer.

O principal objetivo desta pesquisa foi verificar o nível de pressão sonora existente em Shopping Center's na cidade de João Pessoa e o resultado foram que todos os locais avaliados encontram-se com índices considerados elevados, ou seja, acima do limite permitido pelo Conselho Nacional de Meio Ambiente $n^{\circ} 001 / 90$ que é $50 \mathrm{~dB}(\mathrm{~A})$ restaurantes, $60 \mathrm{~dB}(\mathrm{~A})$ atividades esportivas e $45 \mathrm{~dB}(\mathrm{~A})$ cinemas. 
Os níveis de pressão sonora encontrados variaram de $73.2 \mathrm{~dB}(\mathrm{~A})$ a $92.2 \mathrm{~dB}(\mathrm{~A})$. Na praça de alimentação a variação foi de $85 \mathrm{~dB}(\mathrm{~A})$ a $92.2 \mathrm{~dB}(\mathrm{~A})$, nas salas de jogos eletrônicos foi de 90.6 $\mathrm{dB}(\mathrm{A})$ a $91.6 \mathrm{~dB}(\mathrm{~A})$ e nos cinemas foi de $73.2 \mathrm{~dB}(\mathrm{~A})$ a $90.2 \mathrm{~dB}(\mathrm{~A})$. Os níveis sonoros encontrados são suficientemente intensos para prejudicar a audibilidade de uma conversação podendo contribuir para gerar desconforto e aumentar o estresse na população a eles exposta. Estes resultados atentam para o fato de que a população em geral está sujeita à riscos auditivos e extra-auditivos decorrentes da exposição a níveis de pressão sonora elevados nos ambientes de lazer, o que demonstra a relevância da atuação fonoaudiológica na prevenção das perdas auditivas induzidas por esta exposição.

\section{Referências}

ALVARES, P. A. S.; PIMENTEL-SOUZA F. Diagnóstico de ruído urbano de Belo Horizonte. SMMA, Belo Horizonte, 1988.

ÁlVARES, P. A. S.; PIMENTEL-SOUZA F. Até onde chega a poluição sonora em Belo Horizonte. Rev. Acústica Vibrações, 10:23-42. 2p. 1992.

BRASIL. Ministério do Trabalho. Portaria $n^{\circ}$ 3214/78, NR - 15. Disponível em: <http://www.portal.saude.gov.br> . Acessado em 10 de fevereiro de 2006.

CARMO, L. I. C. Efeitos do Ruído Ambiental no Organismo Humano e suas Manifestações Auditivas. Goiânia. Dissertação (Especialização em Audiologia Clínica) do Centro de Especialização em Fonoaudiologia Clínica - CEFAC. 1999.

FERREIRA JÚNIOR, M. PAIR : bom senso e consenso. São Paulo: VK,. 26-27p. 1998.

FIORINI, A C. A importância do monitoramento audiométrico no programa de conservação auditiva. Revista de Acústica e Vibrações. Vol. 13, julho, p. 95-102 Florianópolis. 1994.

FUNDAÇÃO CENTRO TECNOLÓGICO DE MINAS GERAIS. Desenvolvimento metodológico técnicas de medição e avaliação de ruídos urbanos. Belo Horizonte. CETEC 1987.

FUNDACENTRO. Segurança e Medicina do Trabalho -. Riscos físicos. CETEC. São Paulo. 112p. 1995.

GEREGES, S. N. Y. Ruído: fundamentos e controle. 2ª ed. Florianópoles. 1992.

IBGE Instituto Brasileiro de Estatística Disponível em: <http://www.ibge.gov.br/cidadesat/topwindow.htm?1> . Acessado em 20 de maio de 2007. 2004.

IIDA, I. Ergonomia: Projeto e Produção. Ed. Edgard Blucher LTDA, São Paulo. 1990.

MACEDO, R. Manual de higiene do trabalho na indústria. Lisboa: Fundação Calouste Gulbenkian. 1988.

MELNIK, W. - Saúde Auditiva do Trabalhador. In: KATZ, J. Tratado de Audiologia Clínica. 4 ed. São Paulo: Manole. 529 - 547p. 1999.

MORAES, A. G.; REGAZZONI, R. D. Perícia e avaliação de ruído e calor passo a passo - Teoria e prática. Rio de Janeiro. 2002.

MOSCI, A. S. DINIZ, J. L. C. P. Estudo da exposição ao ruído: impacto no policial militar do Batalhão de Trânsito. Curso de Aperfeiçoamento de Oficiais - QOS/97, Belo Horizonte. 1997. 
OPAS - ORGANIZACION PANAMERICANA DE LA SALUD. Critérios de salud ambiental 12: el ruído. Washington, E.U.A. 1983.

PIMENTEL-SOUZA, F. Efeitos da poluição sonora no sono e na saúde em geral - ênfase urbana. Revista Brasileira de Acústica e Vibrações. Vol. 10. 1993.

RODRIGUES G. L. Poeira e ruído na produção de brita a partir de basalto e gnaisse nas regiões de Londrina e Curitiba, Paraná: incidência sobre trabalhadores e meio ambiente. - Tese Doutorado em Geologia - Universidade Federal do Paraná. Curitiba. 2004.

RUSSO, I. C. P. et. al. Um estudo comparativo sobre os efeitos da exposição à música em músicos de Trio Elétrico. Revista Brasileira de Otorrinolaringologia. Vol. 61, $\mathrm{n}^{\circ}$ 6. 1995.

SANTOS, T. M. M., RUSSO, I. P. A Prática da Audiologia Clínica. São Paulo: Cortez. 1993.

\begin{abstract}
The hearing is a sensory organ by which the body perceives the mechanical waves produced by a body's vibration, spreading itself through molecules of air, or the sound. When a sound is unwanted and compromisses the health and well being of people, this is called by noise. The purpose of this work was to verify the existent level sound pressure in four Shopping Mall Centers in the city of Joao Pessoa and to compare with the permitted, through the resolution /Conama / Article 001, 08 of March of 1990. The used methodology was the collect of data being developed in stages. This study is quantitative of exploratory and cross nature. According to the actual research, it was verified that the noise is present in these four places of entertainment of the city of Joao Pessoa. It concludes that people who are often in these places does not know the contents of noise, the maximum limits allowed by law, and still, the effects of noise in the organism. The data collected in this research may serve as subsidies for changing the posture ahead of the presented results.
\end{abstract}

Key-words: level; sonorous pressure; noise.

Inserir aqui dados completos de TODOS os autores:

Nome completo: Valéria de Sá Barreto Gonçalves

Filiação institucional:

Departamento:

Função ou cargo ocupado:

Endereço completo para correspondência: Rua: São Gonçalo, No1021, $\operatorname{Apt}^{\mathrm{o}}$ 403. Bairro:

Manaíra. Cidade: João Pessoa - Paraíba - Brasil. CEP: 58.038 -330.

Telefones para contato: (0XX83) 9372-0943

e-mail: lelajp@terra.com.br

Nome completo: Paulo José Adissi

Filiação institucional: Professor Adjunto da Universidade Federal da Paraíba (UFPB)

Departamento: Programa da Pós-graduação em Engenharia de Produção (PPGEP)

Função ou cargo ocupado: Coordenado do Curso de Pós-Graduação em Engenharia de Produção. 
Endereço completo para correspondência: Centro de Tecnologia da UFPB.

Telefones para contato: (0XX83) 3216-7124

e-mail: adissi@ct.ufpb.br 